\title{
Influences of Risk Perception and Sense of Place on Landslide Disaster Preparedness in Southwestern China
}

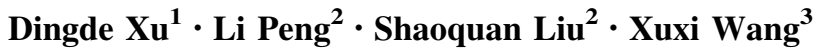

Published online: 24 April 2018

(C) The Author(s) 2018

\begin{abstract}
The effects of risk perception and sense of place on disaster preparedness have been widely reported. However, most studies have only demonstrated weak relationships and it is unknown whether these are applicable to China. This study investigated such relationships in hazard-threatened areas of the Three Gorges Reservoir area in southwestern China. Data were collected from 348 farming households in landslide-prone areas. Binary logistic and Tobit regression models were constructed to determine whether risk perception and sense of place influence landslide preparedness. The results show that: (1) Farming households' awareness of the need to prepare for disasters was relatively low, and disaster preparedness behaviors were mainly based on self-learning. Among the 348 sampled households, $67 \%$ exhibited no disaster preparedness behavior, and only $2 \%$ adopted four of the five types of disaster preparedness behaviors. About a quarter of farming households consciously learned disaster-related knowledge. (2) Risk perception and sense of place had important influences on disaster preparedness. Respondents
\end{abstract}

Dingde $\mathrm{Xu}$ and $\mathrm{Li}$ Peng contributed equally to this work and should be considered co-first authors and corresponding authors.

Dingde $\mathrm{Xu}$

dingdexu@126.com

$\triangle$ Li Peng

pengli@imde.ac.cn

1 Sichuan Center for Rural Development Research, College of Management of Sichuan Agricultural University, Chengdu 611130, China

2 Institute of Mountain Hazards and Environment, Chinese Academy of Sciences, Chengdu 610041, China

3 College of Land and Resources, China West Normal University, Nanchong 637000, China who received higher scores on the perception of the probability of a landslide, the threat of a landslide, and the place dependence variables were more likely to adopt a greater number of disaster preparedness behaviors. Respondents with higher scores on the perception of controllability in the case of a landslide were less likely to adopt a greater number of disaster preparedness behaviors. Additionally, individual and household socioeconomic characteristics-education, loss, distance from hazard site, information acquisition channel, and housing materialwere all related to household disaster preparedness behavior. This study contributes to the current literature by improving the understanding of the relationships of risk perception and sense of place to disaster preparedness in farming households threatened by geological disasters in southwestern China.

Keywords China - Disaster preparedness - Risk perception - Sense of place - Three Gorges Reservoir area

\section{Introduction}

The Rural Revitalization Strategy ${ }^{1}$ was put forward at the 19th National Congress of the Communist Party of China (CPC) in October 2017 as a general policy for building rural areas with thriving businesses, pleasant living environments, social etiquette and civility, effective governance, and prosperity, with the immediate primary task of alleviating poverty. By the end of 2017, there were 30 million impoverished rural people in China who mainly

\footnotetext{
$\overline{1}$ http://dcz-china.org/news/china-is-pursuing-a-new-rural-vitaliza tion-strategy.
} 
live in some concentrated contiguous poor areas. Affected by geology and topography, geological disasters are frequent in some rural communities in these areas, seriously threatening people's lives and property (Xu et al. 2017a). Unlike other factors leading to poverty, geological disasters are characterized by their infrequent occurrence, their abrupt occurrence, and their high degree of severity. These factors can instantly deplete the wealth of farming households that may have been accumulated over decades (Xu et al. 2017b). In 2016, China recorded 9710 cases of geological disasters, with landslides accounting for $76.2 \%$ of the total. These disasters caused 370 deaths, 35 missing people, 209 injured people, and a direct economic loss of USD 460 million (Geological Disaster Emergency Response Directing Center of Ministry of Land and Resources 2016). Moreover, disasters are becoming more numerous and widely distributed, increasingly leading to longer-term fears of disaster compared to before (Xu et al. 2017a). Research on geological disasters is urgently needed to achieve the central government's poverty eradication target by 2020 .

Many scholars have given great attention to the impact of disasters on households and their responses (including relocation, disaster preparedness, and so on) (Lindell and Perry 2000; Han and Nigg 2011; Tobin et al. 2011; Lindell 2013; Hernández-Moreno and Alcántara-Ayala 2017; Xu et al. 2017a). But many existing empirical studies have focused more on floods (Lindell and Hwang 2008; Lawrence et al. 2014), earthquakes (Guo et al. 2014; McClure et al. 2015; Han et al. 2017; Cui et al. 2018), hurricanes (Peacock et al. 2005), and volcanos (Guo 2008; Jones et al. 2013), with little attention directed at landslides. Most studies that have focused on landslides in recent years were conducted in urban regions. Few studies have dealt with rural populations located in landslide-threatened areas (Butler and DeChano 2012; Calvello et al. 2016), especially areas exposed to disasters as well as poverty in developing countries (Xu et al. 2017a).

Disaster preparedness is a common behavioral response of households to natural hazard-induced disasters. Generally, households with adequate disaster preparedness can effectively reduce the impacts of disasters (Lindell and Perry 2000; Lindell 2013; Han et al. 2017). Some empirical studies from the United States have demonstrated that USD 1 of investment in mitigation and preparedness could save society USD 4 in losses (Godschalk et al. 2009; Han et al. 2017). However, the general conclusion from the existing literature is that although it varies, the level of household preparedness is generally not very high (Mishra et al. 2010; Kohn et al. 2012; Adiyoso and Kanegae 2014; Roder et al. 2016; Hoffmann and Muttarak 2017). The mainland of China, especially regions where geological disasters and poverty are intertwined, urgently needs relevant research to investigate this issue.

To be able to promote household disaster resilience, it is also crucial to understand the underlying factors that affect household preparedness. However, there are relatively few empirical studies on the determinants of disaster preparedness in developing countries (Hoffmann and Muttarak 2017), and little is known about this issue in China. Although risk perception is often regarded as an important factor affecting disaster preparedness in farming households, due to the inconsistency of measurement standards, the results of different studies are not consistent. Most studies suggest that there is only a weak correlation or no significant correlation between risk perception and disaster preparedness (Lindell and Whitney 2000; Siegrist and Gutscher 2006). The effects of sense of place on farming households' disaster preparedness are also unclear. Thus, for China's geological disaster areas the question remains: What is the relationship between risk perception, sense of place, and farming households' disaster preparedness?

The Three Gorges Reservoir area in China is a mountainous region with high poverty and return-to-poverty rates, and subject to frequent geological disasters (Xu et al. 2017b). This study is based on a survey of farming households and explores the relationship between household risk perception, sense of place, and the disaster preparedness behavior of farming households, so as to inform disaster prevention policies. It attempts to answer two questions:

(1) What percentage of farming households in southwestern China's geological disaster zone is prepared for landslide disasters? and

(2) What are the specific impacts of risk perception and sense of place on the disaster preparedness of farming households? $?^{2}$

\section{Literature Review}

Household disaster preparedness and its influencing factors have been a topic of geography and one of the central focuses of disaster studies. Lindell and Perry (2000), Kohn et al. (2012), and Lindell (2013) have systematically

\footnotetext{
$\overline{2}$ This study is a continuation of Xu et al. (2017a) on "Influences of Sense of Place on Farming Households' Relocation Willingness in Areas Threatened by Geological Disasters: Evidence from China" published in this journal. In that article, we explored the relationship of risk perception and sense of place to the relocation willingness of farming households. The core variables of this study (risk perception and sense of place) are referenced to that article, while the core theme of this study is to analyze the characteristics of disaster preparedness of farming households and explore the relationship of risk perception and sense of place to the disaster preparedness of farming households.
} 
reviewed household responses to environmental hazards. Lindell (2013) clustered the factors that influence household protective behaviors into three categories-risk perception, hazard adjustment attributes, and stakeholder characteristics. In this study, the factors that affect household disaster preparedness are often divided into individual and household socioeconomic characteristics, risk perception, and sense of place.

The results of many empirical studies indicate that residents' disaster preparedness and its drivers are closely related to respondents' individual and household socioeconomic characteristics, their own disaster experiences, and so on. But Lindell's (2013) review pointed out that demographic variables continue to be unreliable predictors of hazard adjustment adoption, and the specific mechanism of how these factors influence residents' disaster preparedness behaviors is not uniform, but mainly depends on their respective environment (Miceli et al. 2008; Hoffmann and Muttarak 2017). Some studies have found that respondents with stable housing tenure, higher income, longer years of education, more children, longer residence time, and who are older, married, and/or are women, are more likely to be prepared for a disaster (Edwards 1993; Russell et al. 1995; Beringer 2000; Collins 2008; Basolo et al. 2009; Fischer 2011; Brenkert-Smith et al. 2012; Reininger et al. 2013). Other studies have obtained different results. Edwards (1993) could find no significant correlation between age and earthquake prevention preparedness, and Fischer (2011) concluded that older elderly people are less likely to be prepared for a disaster. Lindell and Hwang (2008) and Miceli et al. (2008) found no association between education and preparedness. However, preparedness was significantly correlated with disaster experience, escape experience, the distance between home and the disaster point, and risk perception (Lindell and Hwang 2008; Baker 2011). Residents who had suffered disasters more recently (Perry 1979) and directly (Tierney 1993) and had suffered severe losses (Weinstein 1992; Hoffmann and Muttarak 2017) were more likely to be prepared for a disaster (Riad and Norris 1998).

Households make corresponding behavioral decisions only when they perceive the threat of a disaster (Lazo et al. 2015; Xu et al. 2017b). Thus, household risk perception also affects their behavioral decisions, such as relocation and disaster preparedness (Xu et al. 2017a). Lindell's (2013) review concluded that risk perception has a mixture of significant and insignificant correlations with hazard adjustment adoption. The empirical results of studies on risk perception and disaster preparedness are not consistent due to the different measures used to assess risk perception (Xu et al. 2016, 2017a; Peng et al. 2017). Some studies have found a weak or insignificant correlation between risk perception and disaster preparedness (Lindell and Whitney
2000; Siegrist and Gutscher 2006), others have reported that higher levels of perceived risk are associated with increased preparedness behavior (Miceli et al. 2008; Martin et al. 2009; Paul and Bhuiyan 2010; McNeill et al. 2013). Siegrist and Gutscher (2006) demonstrated that perceived risk did not influence prevention behaviors in coping with flood disasters. Miceli et al. (2008) found no significant relationship between likelihood of disaster judgments and adoption of protective behaviors, but feelings of worry were associated with disaster preparedness. McNeill et al. (2013) found that the perceived threat severity was positively associated with disaster preparedness, while the relationship between perceived threat likelihood and disaster preparedness was not robust.

Besides risk perception and individual and household characteristics, the relationship between disaster preparedness and the emotional connection between the individual and the environment (for example, community ties, place attachment, and sense of place) is also one of the focuses of research (Mishra et al. 2010; Harvatt et al. 2011; Anton and Lawrence 2016). Bachrach and Zautra (1985), Tierney et al. (2001), Mishra et al. (2010), and Anton and Lawrence (2016) found that households with stronger attachment to a place or community were more likely to be prepared for disasters. Duncan and Newman (1975), Kiecolt and Nigg (1982), and Riad and Norris (1998) claimed that individuals who intended to move were less embedded in the community. Brenkert-Smith et al. (2006) suggested that residents weigh the relationship between the need for disaster prevention behavior and sense of place, that is their attachment to place, as well as their true feelings of living in a threat area, and unless they are directly threatened by disaster, they are unwilling to prepare for one.

The literature review shows that studies often explore disaster preparedness and its influencing factors in terms of individual and household characteristics, risk perception, and sense of place. However, the results of different empirical studies are not consistent. Using survey data from rural farming households in the Three Gorges Reservoir area, this study constructs econometric models to explore the specific impacts of risk perception and sense of place on disaster preparedness.

\section{Data Source and Methods}

The Three Gorges Reservoir area is an important part of the upper reach of the Yangtze River economic zone. The per capita net income of the rural residents was RMB 8441 Yuan (USD 1379) in 2014, about 15\% lower than the national average for China's rural population (Chongqing Municipal Bureau of Statistics 2015; CNSB 2015). Eight of the area's counties (Wuxi County, Wushan County, Fengjie 
Table 1 Summary statistics for households facing disaster threats in the sample villages in the Three Gorges Reservoir study area

\begin{tabular}{|c|c|c|c|c|}
\hline Sample county & Sample town & Sample village & Number of households facing disaster threats & Sampled households \\
\hline \multirow[t]{6}{*}{ Wanzhou district } & \multirow[t]{2}{*}{ Xikou } & Qilin & 46 & 20 \\
\hline & & Yuzu & 148 & 30 \\
\hline & \multirow[t]{2}{*}{ Xinxiang } & Longquan & 154 & 35 \\
\hline & & Zhihua & 174 & 35 \\
\hline & \multirow[t]{2}{*}{ Yanshan } & Wanshun & 47 & 20 \\
\hline & & Quanshui & 128 & 35 \\
\hline \multirow[t]{5}{*}{ Fengjie county } & \multirow[t]{3}{*}{ Zuyuan } & Chahe & 306 & 38 \\
\hline & & Wushan & 364 & 40 \\
\hline & & Caoping & 438 & 40 \\
\hline & \multirow[t]{2}{*}{ Dashu } & Guanshan & 50 & 20 \\
\hline & & Shiyan & 200 & 35 \\
\hline Total & & & 2055 & 348 \\
\hline
\end{tabular}

County, Kai County, Wanzhou District, Shizhu County, Wulong County, and Fengdu County) are listed as key national poverty-alleviation counties (Peng et al. 2017). Due to the limitations of the terrain, many settlements in the Three Gorges Reservoir area are located in geological hazard-threatened areas, and some settlements are located at sites-for example, on debris flow fans-where geological hazards have occurred before.

\subsection{Data Source}

This study mainly used data from a survey conducted in August 2015 in the Three Gorges Reservoir area. The investigation largely focused on the situation of farming households in 2014 regarding disaster preparedness, individual characteristics, household characteristics, risk perception, and sense of place. Each survey questionnaire took approximately $1 \mathrm{~h}$ to complete for an average respondent. The survey sample was selected using a combination of stratified sampling and equal-probability random sampling.

The focus of this research was to explore the influences of risk perception and sense of place on the disaster preparedness of farming households. Considering the variations in geology, populations at risk, and economic development levels, the study randomly classified the 19 counties into two categories: those with more threatened people and low economic development (11 counties); and those with fewer threatened people and high economic development (8 counties). One county was selected from each category, resulting in two sample counties: Wanzhou (fewer threatened people and high economic development) and Fengjie (more threatened people and low economic development), which included 48 townships in both counties. Considering the number of farming households threatened, as well as the economic development level in the geological disaster-threatened area, we selected three townships from Wanzhou and two townships from Fengjie. According to the number of farming households threatened by geological disasters as provided by the village cadres, ${ }^{3}$ we divided the 37 villages in the five selected townships into two groups: high geological disaster threat villages and low geological disaster threat villages. Then one village was selected from each group in each of the five townships. Considering the overall representativeness of the sample, we selected one more high geological disaster threat village from this sample of townships. In total, we obtained 11 sample villages. In the 11 sample villages, according to the geological disaster threat list provided by the village cadres, 2055 farming households were threatened by geological disasters. We selected 20-40 threatened households from each village for the survey. Finally, we used a convenience sampling method to select the sample respondents; each household selected a respondent who was familiar with the basic situation of the family to answer the survey questionnaire. Ten investigators with prior training 4 each conducted household questionnaire surveys in 2-4 households per sample village. Eventually, 348 valid questionnaires were generated with a completion rate of $100 \%$. Summary statistics for households facing disaster threats in the sample villages are shown in Table 1.

\footnotetext{
${ }^{3}$ Village cadre is the leader of the community, who knows the community well and has all the statistics of the community. We obtained the statistical data through face to face interview with the village cadres.

${ }^{4}$ Before the formal investigation, the 10 investigators received professional training from experienced teachers of the College of Management at Sichuan Agricultural University, and the training content included basic interview etiquette, basic skills for asking questions, the logical consistency of the questionnaire, and so on.
} 


\subsection{Methods}

Considering the distribution characteristics of the dependent variables, this study constructed five binary logistic regression models and a Tobit regression model to explore the impacts of risk perception and sense of place on behaviors $Y 1-Y 5$ and $Y 6$.

\subsubsection{Selection and Definition of Model Variables}

The dependent variables of this study concern farming households' disaster preparedness behaviors and whether the farming households have adopted five disaster preparedness behaviors: (1) prepare some necessary items to avoid disaster impact; (2) learn knowledge of disaster prevention and mitigation; (3) participate in government organized disaster-related training and drills; (4) make some changes to home; and (5) purchase any kind of insurance against natural hazard-induced disasters. The final variable is the total number of adopted disaster preparedness behaviors. These variables were selected based on previous research on the measurement of farming households' disaster preparedness (Mulilis et al. 1990; Russell et al. 1995; Miceli et al. 2008; Basolo et al. 2009; McNeill et al. 2013; Anton and Lawrence 2016; Hoffmann and Muttarak 2017), in combination with the actual situation of the study area. For the first five preparedness variables, where a household is prepared in a particular way, a code of 1 was assigned, otherwise, 0 was assigned (Table 2). The total number of the five types of preparedness behaviors that a farming household adopted was then counted, resulting in a value of $0-5$.

Risk perception is one of the core independent variables investigated by this study. Although there is already a large number of studies that have measured household risk perception via the psychometric paradigm method, different scholars still hold different views about household risk perception (Xu et al. 2016). Some scholars choose to measure risk perception based on a single dimension, such as the intensity of residents' overall feeling (He and Zhai 2015), the degree of threat to family assets and personal security (Lindell and Hwang 2008; Calvello et al. 2016), or the future possibility of a hazard occurring (Butler and DeChano 2012). Others hold that disaster risk perception is a multidimensional concept (Lindell and Perry 2003; Armaş and Avram 2008; Xu et al. 2016). Slovic (1987) indicated that risk perception is mainly composed of unknown risk and dread risk. The former is highly related to the degree of uncontrollability and the potential for dread; while the latter is closely related to curiosity, scientific knowledge, and impacts. The measurement of risk perception in this study draws from the psychometric paradigm of Slovic (1987) that measures the dimensions of risk perception using ratings. Xu et al. (2016) proposed five dimensions: probability, worry, unknown, controllability, and threat. Table 3 shows the specific measurement of risk perception. Using Cronbach's alpha to test the reliability of Probability, Worry, Unknown, Controllability, Threat, and risk perception measurements, the total scales are 0.70 , $0.76,0.71,0.68,0.67$ and 0.67 respectively, which are within the acceptable range and indicate that these measurements are applicable for subsequent analysis.

Sense of place is another focus variable of this study, and the measurement draws from Jorgensen and Stedman's (2001) classic study. Sense of place is divided into three dimensions: place dependence, place attachment, and place identity. On this basis, specific measurements were designed to measure the various dimensions of sense of place (Table 4). Using Cronbach's alpha to test the reliability of Place dependence, Place attachment, Place identity, and sense of place measurements, the total scales are $0.82,0.74,0.75$, and 0.86 , respectively, which are within the acceptable range and indicate that these measurements are applicable for subsequent analysis.

The control variables that affect the disaster preparedness behavior of farming households draw from the research of Edwards (1993), Russell et al. (1995), Beringer (2000), Collins (2008), Miceli et al. (2008), Basolo et al. (2009), Fischer (2011), Brenkert-Smith et al. (2012), McNeill et al. (2013), Anton and Lawrence (2016), Han et al. (2017), and Hoffmann and Muttarak (2017). The variables include years of education of the respondent

Table 2 Frequency of households who adopted each disaster preparedness behavior in the Three Gorges Reservoir study area $(n=348)$

\begin{tabular}{|c|c|c|}
\hline Preparedness Behavior & Frequency & Percent \\
\hline $\begin{array}{l}\text { Household prepared some necessary items to avoid disaster impact, such as store emergency food and water supplies, } \\
\text { keep a working flashlight }(0=\text { no, } 1=\text { yes })\end{array}$ & 42 & 12.07 \\
\hline Household learned knowledge of disaster prevention and mitigation in private $(0=$ no, $1=$ yes $)$ & 90 & 25.86 \\
\hline $\begin{array}{l}\text { Household participated in government organized disaster-related training and drills, such as escape drills }(0=\text { no, } \\
1=\text { yes })\end{array}$ & 29 & 8.33 \\
\hline Household made some changes to home, such as reinforcing buildings $(0=$ no, $1=$ yes $)$ & 24 & 6.90 \\
\hline Household purchased any kind of insurance against natural hazard-induced disasters $(0=$ no, $1=$ yes $)$ & 5 & 1.44 \\
\hline
\end{tabular}


Table 3 Risk perception measurement in the Three Gorges Reservoir study area

\begin{tabular}{|c|c|c|c|c|}
\hline Code & $\begin{array}{l}\text { Risk perception } \\
\text { dimension }\end{array}$ & Description $^{\mathrm{a}}$ & Mean & $\mathrm{SD}^{\mathrm{b}}$ \\
\hline A1 & Probability & In the next decade, there is a great possibility that a landslide will occur around your house. & 3.39 & 1.03 \\
\hline A2 & & You have the constant feeling that a landslide will happen one day. & 3.53 & 1.05 \\
\hline A3 & & Compared to others', there is a higher possibility that a landslide will attack your house. & 3.41 & 1.05 \\
\hline A4 & & There are more and more obvious signals of landslides in recent years. & 3.80 & 1.08 \\
\hline A5 & Worry & Upon thinking about landslides, you will feel scared & 4.39 & 0.89 \\
\hline A6 & & You are worried about the influence of landslides to your household and the village & 4.45 & 0.75 \\
\hline A7 & Unknown & Once a landslide occurs, you have to resign yourself to fate & 3.50 & 1.19 \\
\hline A8 & & You think that a landslide is determined by fate & 3.73 & 1.13 \\
\hline A9 & & Once a landslide comes, you feel everything is ruined & 3.43 & 1.25 \\
\hline A10 & Controllability & Landslides are controllable through proper methods (like structural projects). & 2.78 & 1.16 \\
\hline A11 & & With the mass monitoring and prevention system, you are not scared of the landslide at all & 3.67 & 0.99 \\
\hline A12 & & $\begin{array}{l}\text { Despite of the uncontrollability of disaster occurrence, you still can reduce loss via proper } \\
\text { preventions. }\end{array}$ & 3.32 & 1.10 \\
\hline A13 & Threat & $\begin{array}{l}\text { In the next decade, your house and land will be subject to disaster upon the occurrence of a } \\
\text { landslide }\end{array}$ & 3.99 & 0.96 \\
\hline A14 & & $\begin{array}{l}\text { In the next decade, the safety of you and your families will be threatened upon the occurrence of } \\
\text { a landslide }\end{array}$ & 3.98 & 0.90 \\
\hline
\end{tabular}

${ }^{\mathrm{a}} 1$ = totally agree, 2 = agree, $3=$ neutral, $4=$ disagree, $5=$ totally disagree

${ }^{\mathrm{b}} \mathrm{SD}=$ Standard deviation

Table 4 Sense of place measurement in the Three Gorges Reservoir study area

\begin{tabular}{|c|c|c|c|c|}
\hline Code & $\begin{array}{l}\text { Sense of place } \\
\text { dimension }\end{array}$ & Description $^{\mathrm{a}}$ & Mean & $\mathrm{SD}^{\mathrm{b}}$ \\
\hline B1 & \multirow[t]{4}{*}{ Place identity } & I do not want to move from here, because I am used to the lifestyle here & 3.97 & 0.98 \\
\hline B2 & & $\begin{array}{l}\text { I am afraid of the disaster, but I still do not want to move away from here, because my roots are } \\
\text { here }\end{array}$ & 3.90 & 1.12 \\
\hline B3 & & I do not think I can be separated from the village and the people in the village & 3.72 & 1.08 \\
\hline B4 & & I never thought that I would move out of the village and live in other places & 3.33 & 1.31 \\
\hline B5 & \multirow[t]{3}{*}{ Place dependence } & I feel proud of living in this village & 3.59 & 1.10 \\
\hline B6 & & Compared with other places, living in this village makes me feel more satisfied & 3.72 & 1.03 \\
\hline B7 & & My love for this village is deeper than that for anywhere else & 3.74 & 1.01 \\
\hline B8 & \multirow[t]{3}{*}{ Place attachment } & When going out, I always think of the village where I live & 4.32 & 0.73 \\
\hline B9 & & Unless going out to do some errands, I usually prefer to stay in the village & 4.06 & 0.79 \\
\hline B10 & & I feel that I can really be myself in the village & 4.27 & 0.75 \\
\hline
\end{tabular}

${ }^{\mathrm{a}} 1$ = totally agree, 2 = agree, $3=$ neutral, 4 = disagree, $5=$ totally disagree

${ }^{\mathrm{b}} \mathrm{SD}=$ Standard deviation

(years); whether a landslide has been experienced by the household $(0=$ no, $1=$ yes $)$; gender of the respondent ( 0 = male, 1 = female); age of the respondent (years); family cash income (Yuan per year); number of persons available for assistance when in urgent need of money; whether there is economic loss from a landslide $(0=$ no, 1 = yes $)$; distance to the hazard site $(<10 \mathrm{~m}=1$, otherwise $=0)$; communication channels to obtain landslide information ( 1 = only from oneself or relatives and friends,
$2=$ only from the government or media, $3=$ from both 1 and 2); number of family members; whether the household has children below $18(0=$ no, $1=$ yes $)$; whether the household has older people above $65(0=$ no, $1=$ yes $)$; and housing material $(1=$ concrete, other $=0)$. Descriptive statistics for each variable are shown in Sect. 4. 


\subsubsection{The Models}

This study contains six dependent variables: five dichotomous variables on whether the farming households had adopted the five disaster preparedness behaviors $(Y 1-Y 5)$, and a count variable - the total number of adopted disaster preparedness behaviors $(Y 6$, with value range $0-5)$. Considering the distribution characteristics of the dependent variables, this study constructed a binary logistic regression model and a Tobit regression model to explore the impacts of risk perception and sense of place on behaviors $Y 1-Y 5$ and $Y 6$. To avoid the influence of heteroscedasticity of the independent variables on the results, robust standard errors were used. The expressions are:

$\begin{aligned} \operatorname{Logit}(Y 1)= & \alpha_{0}+\alpha_{1 i} \times \mathrm{RP}_{i}+\alpha_{2 i} \times \mathrm{SOP}_{i}+\alpha_{3 i} \\ & \times \text { Control }_{i}+\varepsilon_{i} ;\end{aligned}$

Tobit $(Y 2)=b_{0}+b_{1 i} \times \mathrm{RP}_{i}+b_{2 i} \times \mathrm{SOP}_{i}+b_{3 i}$ $\times$ Control $_{i}+\mu_{i}$;

where $\alpha_{0}, b_{0}$ refer to constant term; $\alpha_{1 i}, \alpha_{2 i}, \alpha_{3 i}, b_{1 i}, b_{2 i}, b_{3 i}$ are parameters need to be estimated; $\varepsilon_{i}, \mu_{i}$ refer to model residuals; $R P$ refers to risk perception, $S O P$ refers to sense of place, and Control refers to the control variables. Modeling was achieved using Stata 15.0.

\subsubsection{Research Hypotheses}

Based on the existing literature and a comprehensive consideration of the actual situation of the Three Gorges Reservoir area, this study put forward three research hypotheses:

H1 Risk perception has a significant relationship with disaster preparedness. Respondents with a higher perception of Probability, Threat, Worry, and fear of the Unknown are more likely to show disaster preparedness and adopt more types of disaster preparedness behavior; respondents with a higher perception of Controllability are less likely to show disaster preparedness and adopt fewer types of disaster preparedness behavior.

H2 Respondents with higher scores on sense of place (Place dependence, Place attachment, and Place identity) are more likely to show disaster preparedness, and adopt more types of disaster preparedness behavior.

H3 Individual and household characteristics are all significantly correlated with disaster preparedness, but the directions of the influences are unknown.

\section{Results}

This section presents a simple descriptive statistical analysis of the variables involved in the models then builds empirical econometric models to explore the mechanism of influence of risk perception and sense of place in the disaster preparedness decision making of farming households.

\subsection{Descriptive Statistics of the Variables}

Table 2 shows the frequency of households who adopted each disaster preparedness behavior. It indicates that among the five types of disaster preparedness behaviors, 90 farming households consciously learned disaster-related knowledge, accounting for $25.86 \%$ (the largest proportion) of the total sample. Next, 42 households prepared some necessary items to avoid disaster impact, accounting for $12.07 \%$ (the second-largest proportion) of the total sample, while only 5 households purchased disaster-related insurance, accounting for $1.44 \%$ (the smallest proportion) of the total sample. Tables 3 and 4 present raw data on risk perception and sense of place.

Table 5 shows the descriptive statistics for the variables involved in the modeling. To enable modeling using the binary logistic regression model and the Tobit regression model, the mean and standard deviation of the dependent variables were calculated; and the raw scores of risk perception and sense of place in Tables 3 and 4 were normalized through factor analysis for dimensionality reduction. In order to facilitate the interpretation of the results, we used the efficiency coefficient method to convert the scores of each dimension factor to achieve the present results. For risk perception, the mean score of Worry ranks first and that of Probability ranks last; for sense of place, the mean scores of the three variablesPlace dependence, Place identity, and Place attachmentare 59.68, 67.81, and 69.88, respectively. For individual and household characteristics, $36 \%$ of the interviewees were female, the average age of all interviewees was 57.66 years, and the average number of years of education was 4.98 years. Some $88 \%$ of interviewees had experienced landslides, $26 \%$ of households were located within the red zones $(<10 \mathrm{~m})$ of landslide threat areas, and $68 \%$ had experienced economic loss due to landslides. The average family cash income was RMB 44,224 Yuan per annum. Moreover, 59 and $44 \%$ of households included children and older people, respectively. The major information channels for landslide warnings were relatives, friends, and the government. About $77 \%$ of houses were built from concrete (Table 5).

Table 6 shows the frequency distribution of farming households' total number of adopted disaster preparedness 
Table 5 Definition and descriptive statistics of the variables in the models used in the Three Gorges Reservoir area study ${ }^{\mathrm{a}}$

\begin{tabular}{|c|c|c|c|c|}
\hline Category & Variable & Measure & Mean & SD \\
\hline \multirow[t]{6}{*}{ Dependent variables } & Y1 & Household prepared some necessary items $(0=$ no, $1=$ yes $)$ & 0.12 & 0.33 \\
\hline & Y2 & $\begin{array}{l}\text { Household learned knowledge of disaster prevention and mitigation }(0=\text { no, } \\
1=\text { yes })\end{array}$ & 0.26 & 0.44 \\
\hline & Y3 & $\begin{array}{l}\text { Household participated in government organized disaster-related training } \\
\text { and drills }(0=\text { no, } 1=\text { yes }) .\end{array}$ & 0.08 & 0.28 \\
\hline & Y4 & Household made some changes to home $(0=$ no, $1=$ yes $)$. & 0.07 & 0.25 \\
\hline & Y5 & $\begin{array}{l}\text { Household purchased any kind of insurance against natural hazard-induced } \\
\text { disasters }(0=\text { no, } 1=\text { yes })\end{array}$ & 0.01 & 0.12 \\
\hline & Y6 & Total number of adopted disaster preparedness behaviors & 0.54 & 0.93 \\
\hline \multirow[t]{5}{*}{ Risk perception } & Probability & Score for perception of the possibility of a landslide $(1-100)$ & 51.62 & 17.36 \\
\hline & Worry & Score for worry about landslides $(1-100)$ & 73.12 & 15.39 \\
\hline & Unknown & Score for perception of the unknown of a landslide $(1-100)$ & 58.67 & 17.70 \\
\hline & Controllability & Score for perception of controllability in a landslide $(1-100)$ & 52.26 & 18.19 \\
\hline & Threat & Score for perception of threat of a landslide $(1-100)$ & 62.14 & 14.96 \\
\hline \multirow[t]{3}{*}{ Sense of place } & $\begin{array}{l}\text { Place } \\
\text { dependence }\end{array}$ & Score for place dependence $(1-100)$ & 59.68 & 17.53 \\
\hline & Place identity & Score for place identity $(1-100)$ & 67.81 & 15.27 \\
\hline & $\begin{array}{l}\text { Place } \\
\quad \text { attachment }\end{array}$ & Score for place attachment $(1-100)$ & 69.88 & 16.52 \\
\hline \multirow{13}{*}{$\begin{array}{l}\text { Individual and household } \\
\text { characteristics }\end{array}$} & Education & Years of education (years) & 4.98 & 3.26 \\
\hline & Experience & Landslide has been experienced $(0=$ no, $1=$ yes $)$ & 0.88 & 0.33 \\
\hline & Gender & Gender $(0=$ male, $1=$ female $)$ & 0.36 & 0.48 \\
\hline & Age & Age (years) & 57.66 & 10.82 \\
\hline & Income & Family cash income (Yuan $\left.{ }^{\mathrm{b}}\right)$ & 44,224 & 55,542 \\
\hline & Financial help & Number of persons available for assistance when in urgent need of money & 4.63 & 3.28 \\
\hline & Loss & Economic loss from a landslide $(0=$ no, $1=$ yes $)$ & 0.68 & 0.47 \\
\hline & Distance & Distance to the hazard site $(<10 \mathrm{~m}=1$, else $=0)$ & 0.26 & 0.44 \\
\hline & Information & Communication channels to obtain landslide information ${ }^{c}$ & 1.59 & 0.78 \\
\hline & Member & Number of family members & 4.21 & 1.67 \\
\hline & Child & Children $<18(0=$ no, $1=$ yes $)$ & 0.59 & 0.49 \\
\hline & Old & Older people $>65(0=$ no, $1=$ yes $)$ & 0.44 & 0.50 \\
\hline & $\begin{array}{l}\text { Housing } \\
\text { material }\end{array}$ & Housing material $(1=$ concrete, else $=0)$ & 0.77 & 0.42 \\
\hline
\end{tabular}

${ }^{a}$ Risk perception, sense of place, and individual and household characteristics are mainly drawn from the research of Xu et al. (2017a)

${ }^{\mathrm{b}} 1 \mathrm{USD}=6.19$ Yuan (at the time of the study)

${ }^{\mathrm{c}} 1=$ only from oneself or relatives and friends, $2=$ only from the government or media, $3=$ from both 1 and 2

behaviors. Among the 348 sampled households, 234 $(67.24 \%)$ were not prepared at all with regard to the five behaviors, and only $7(2.01 \%)$ adopted four types of disaster preparedness behaviors. In addition, 62, 35, and 10 households adopted 1,2, and 3 types of disaster preparedness behaviors, accounting for 17.82, 10.06, and $2.87 \%$ of the total sample, respectively.

\subsection{Model Results}

Table 7 shows the results of the logistic and Tobit models. Models 1-5 regressed the presence of the five types of disaster preparedness behaviors in households against their potential influencing factors, whereas Model 6 regressed the total number of farming households' adopted disaster preparedness behaviors against its potential influencing factors. Before constructing the models, we examined whether there was multi-collinearity among the independent variables. We found that all variance inflation factors (VIFs) were less than 10, indicating that there was no serious multi-collinearity and that model construction could progress.

The results of Models 1-6 show that household risk perception had a significant relationship with disaster preparedness. However, the significance of the correlations between the different dimensions of disaster risk 
Table 6 Frequency distribution of farming households' total number of adopted disaster preparedness behaviors in the Three Gorges Reservoir study area $(n=348)$

\begin{tabular}{llll}
\hline Number & Frequency & Percent & Cumulative frequency \\
\hline 0 & 234 & 67.24 & 67.24 \\
1 & 62 & 17.82 & 85.06 \\
2 & 35 & 10.06 & 95.11 \\
3 & 10 & 2.87 & 97.99 \\
4 & 7 & 2.01 & 100 \\
Total & 348 & 100 & \\
\hline
\end{tabular}

perception and whether rural households adopted the five disaster prevention preparedness behaviors were not the same.

Based on Model 1, Probability and Unknown both have significantly positive regression coefficients, while Worry has a significantly negative regression coefficient. When everything else remains constant, every one unit increase in Probability and Unknown corresponds to the odds of a "prepared some necessary items" ( $Y 1$, versus not prepared) increase by a factor of 0.03 and 0.02 , respectively; every one unit increase in Worry corresponds to the odds of a "prepared some necessary items" decrease by a factor of 0.03. Based on Model 2, Probability and Threat both have significant positive regression coefficients, while Unknown and Controllability have significant negative regression coefficients. Every one unit increase in Probability and Threat corresponds to the odds of a "learned knowledge of disaster prevention and mitigation" $(Y 2$, versus not learned) increase by a factor of 0.03 and 0.03 , respectively; every one unit increase in Unknown and Controllability corresponds to the odds of a "learned knowledge of disaster prevention and mitigation" (versus not learned) decrease by a factor of 0.02 and 0.03 , respectively. Probability was significantly positively correlated with "participated in government organized disaster-related training and drills" ( $Y 3$, Model 3) and "made some changes to home" (Y4, Model 4). Unknown and Threat both have positive regression coefficients, while Controllability has a negative regression coefficient with "purchased any kind of insurance against natural hazard-induced disasters" ( $Y 5$, Model 5).

Based on Model 6, inconsistent with research hypothesis H1, Worry and Unknown were unrelated to the total number of disaster preparedness behaviors adopted by farming households $(Y O)$. A possible reason is that farming households believe in their luck, thinking that the possibility of a risk affecting them is very small. Hence, they are reluctant to conduct any disaster preparedness, even though they have concerns about disasters. As one respondent in the survey said, "Our village is designated by the government as a landslide threat area, and if a landslide occurs, we will inevitably suffer from the losses, such as the destruction of land, the damage of cob walls and houses by the rush of waters, and so on, but I have lived here for a lifetime (for decades), and a landslide has not occurred and may still not occur. Even if it occurs, it is still some distance away from my home, and my home is less likely to be affected by the disaster, so we don't need to have disaster preparedness."

Table 7 shows that sense of place is an important factor that affects the disaster preparedness of farming households. When everything else remains constant, every one unit increase in Place dependence corresponds to the odds of a "household prepared some necessary items," "household learned knowledge of disaster prevention and mitigation," and "household made some changes to home" increase by a factor of $0.02,0.02$, and 0.04 , respectively ( $Y 1$, Model 1; $Y 2$, Model 2, and $Y 4$, Model 4). Every one unit increase in Place attachment corresponds to the odds of a "household purchased any kind of insurance against natural hazard-induced disasters" increase by a factor of 0.24 (Y5, Model 5). In Model 6, Place dependence was positively related to the total number of disaster preparedness behaviors (Y6). Inconsistent with research hypothesis $\mathrm{H} 2$, no matter which model was used, the relationship between households' Place identity and any household disaster preparedness behavior was not significant.

Consistent with research hypothesis $\mathrm{H} 3$, individual and household characteristics were all significantly correlated with household disaster preparedness behaviors. However, the significance of the correlations between different characteristics and rural households' five disaster preparedness behaviors were not the same. In Model 1 , for example, households prepared some necessary items $(Y 1)$ was only significantly related to Distance; in Model 6, the total number of disaster preparedness behaviors $(Y 6)$ was only significantly related to Education, Distance, Official information, and All information. 
Table 7 Results of regression estimates of household disaster preparedness variables and their potential influencing variables ${ }^{\mathrm{a}}$ in the Three Gorges Reservoir study area

\begin{tabular}{|c|c|c|c|c|c|c|}
\hline \multirow[t]{2}{*}{ Variable } & \multicolumn{5}{|c|}{ Logit Models } & \multirow{2}{*}{$\begin{array}{l}\text { Tobit model } \\
\text { Model } 6\end{array}$} \\
\hline & Model 1 & Model 2 & Model 3 & Model 4 & Model 5 & \\
\hline \multirow[t]{2}{*}{ Probability } & $0.03 * * *$ & $0.03 * * *$ & $0.05 * * *$ & $0.02 *$ & 0.11 & $0.03 * * *$ \\
\hline & $(0.01)$ & $(0.01)$ & $(0.01)$ & $(0.01)$ & $(0.08)$ & $(0.01)$ \\
\hline \multirow[t]{2}{*}{ Worry } & $-0.03 * *$ & -0.00 & 0.01 & -0.02 & -0.05 & -0.01 \\
\hline & $(0.01)$ & $(0.01)$ & $(0.02)$ & $(0.02)$ & $(0.05)$ & $(0.01)$ \\
\hline \multirow[t]{2}{*}{ Unknown } & $0.02 *$ & $-0.02 * *$ & -0.00 & 0.00 & $0.31 * * *$ & -0.01 \\
\hline & $(0.01)$ & $(0.01)$ & $(0.01)$ & $(0.01)$ & $(0.11)$ & $(0.01)$ \\
\hline \multirow[t]{2}{*}{ Controllability } & -0.01 & $-0.03 * * *$ & -0.01 & 0.00 & $-0.31 * *$ & $-0.02 * *$ \\
\hline & $(0.01)$ & $(0.01)$ & $(0.01)$ & $(0.02)$ & $(0.13)$ & $(0.01)$ \\
\hline \multirow[t]{2}{*}{ Threat } & 0.02 & $0.03 * *$ & 0.02 & 0.01 & $0.32 * * *$ & $0.03 * *$ \\
\hline & $(0.02)$ & $(0.01)$ & $(0.02)$ & $(0.02)$ & $(0.12)$ & $(0.01)$ \\
\hline \multirow[t]{2}{*}{ Place dependence } & $0.02 * *$ & $0.02 * *$ & 0.02 & $0.04 * * *$ & 0.04 & $0.02 * * *$ \\
\hline & $(0.01)$ & $(0.01)$ & $(0.01)$ & $(0.02)$ & $(0.03)$ & $(0.01)$ \\
\hline \multirow[t]{2}{*}{ Place identity } & 0.00 & 0.01 & 0.01 & -0.01 & 0.07 & 0.01 \\
\hline & $(0.01)$ & $(0.01)$ & $(0.01)$ & $(0.01)$ & $(0.06)$ & $(0.01)$ \\
\hline \multirow[t]{2}{*}{ Place attachment } & 0.01 & 0.02 & 0.02 & -0.00 & $0.24 * * *$ & 0.02 \\
\hline & $(0.01)$ & $(0.01)$ & $(0.02)$ & $(0.02)$ & $(0.09)$ & $(0.01)$ \\
\hline \multirow[t]{2}{*}{ Education } & 0.03 & $0.10 * *$ & $0.20 * * *$ & 0.12 & 0.14 & $0.09 * *$ \\
\hline & $(0.06)$ & $(0.05)$ & $(0.08)$ & $(0.08)$ & $(0.31)$ & $(0.04)$ \\
\hline \multirow[t]{2}{*}{ Experience $^{c}$} & -0.15 & 0.44 & 0.41 & $1.85^{*}$ & 0.00 & 0.74 \\
\hline & $(0.61)$ & $(0.50)$ & $(0.61)$ & $(1.12)$ & $(0.00)$ & $(0.52)$ \\
\hline \multirow[t]{2}{*}{ Gender $^{\mathrm{c}}$} & -0.49 & -0.20 & -0.28 & -0.17 & $5.43 * * *$ & -0.31 \\
\hline & $(0.38)$ & $(0.32)$ & $(0.44)$ & $(0.59)$ & $(1.95)$ & $(0.29)$ \\
\hline \multirow[t]{2}{*}{ Age } & -0.02 & 0.00 & 0.01 & -0.03 & -0.15 & 0.01 \\
\hline & $(0.02)$ & $(0.02)$ & $(0.02)$ & $(0.02)$ & $(0.15)$ & $(0.02)$ \\
\hline \multirow[t]{2}{*}{ ln (income) } & 0.00 & 0.02 & -0.03 & $-0.31 *$ & $3.25 * *$ & -0.09 \\
\hline & $(0.19)$ & $(0.13)$ & $(0.20)$ & $(0.18)$ & $(1.46)$ & $(0.12)$ \\
\hline \multirow[t]{2}{*}{ Financial help } & 0.05 & 0.04 & 0.03 & -0.09 & $-2.27 * * *$ & 0.03 \\
\hline & $(0.07)$ & $(0.04)$ & $(0.07)$ & $(0.08)$ & $(0.84)$ & $(0.05)$ \\
\hline \multirow[t]{2}{*}{$\operatorname{Loss}^{c}$} & 0.39 & $0.75 * *$ & -0.24 & -0.26 & -0.58 & 0.51 \\
\hline & $(0.47)$ & $(0.38)$ & $(0.51)$ & $(0.54)$ & $(1.41)$ & $(0.36)$ \\
\hline \multirow[t]{2}{*}{ Distance $^{\mathrm{c}}$} & $1.04 * * *$ & $0.75 * *$ & 0.40 & 0.66 & 6.44 & $0.73 * *$ \\
\hline & $(0.38)$ & $(0.30)$ & $(0.38)$ & $(0.50)$ & $(4.04)$ & $(0.30)$ \\
\hline \multirow[t]{2}{*}{ Official information $^{\mathrm{b}}$} & -0.22 & $0.89 * *$ & 0.42 & $2.05 * * *$ & $3.01 *$ & $0.87 * *$ \\
\hline & $(0.52)$ & $(0.35)$ & $(0.47)$ & $(0.59)$ & $(1.80)$ & $(0.36)$ \\
\hline \multirow[t]{2}{*}{ All information ${ }^{b}$} & 0.45 & 0.36 & 0.57 & $1.48 * *$ & 0.00 & $0.84 * *$ \\
\hline & $(0.48)$ & $(0.40)$ & $(0.58)$ & $(0.69)$ & $(0.00)$ & $(0.37)$ \\
\hline Member & -0.13 & 0.14 & 0.27 & $0.41 *$ & $-3.16^{* *}$ & 0.16 \\
\hline & $(0.15)$ & $(0.12)$ & $(0.21)$ & $(0.21)$ & $(1.51)$ & $(0.12)$ \\
\hline Child $^{c}$ & 0.72 & 0.11 & -0.41 & -0.47 & $9.90 * *$ & 0.18 \\
\hline & $(0.52)$ & $(0.37)$ & $(0.65)$ & $(0.69)$ & $(4.14)$ & $(0.37)$ \\
\hline $\mathrm{Old}^{\mathrm{c}}$ & 0.02 & 0.18 & -0.42 & $-0.94 *$ & 0.87 & -0.21 \\
\hline & $(0.44)$ & $(0.33)$ & $(0.49)$ & $(0.53)$ & $(3.67)$ & $(0.32)$ \\
\hline Housing material $^{\mathrm{c}}$ & 0.85 & $-0.62 *$ & 0.10 & $1.67 *$ & 0.00 & -0.04 \\
\hline & $(0.61)$ & $(0.35)$ & $(0.52)$ & $(0.87)$ & $(0.00)$ & $(0.32)$ \\
\hline Constant & $-5.78^{*}$ & $-7.00 * * *$ & $-12.40 * * *$ & $-7.07^{*}$ & $-77.36^{* * *}$ & $-7.39 * * *$ \\
\hline & $(3.11)$ & $(2.45)$ & $(3.37)$ & $(3.63)$ & (28.16) & $(2.28)$ \\
\hline $\operatorname{LR} \operatorname{chi}^{2}\left(\chi^{2}\right)$ & 41.85 & 57.09 & 34.64 & 60.58 & 0.11 & 3.71 \\
\hline
\end{tabular}


Table 7 continued

\begin{tabular}{lllllll}
\hline Variable & \multicolumn{2}{l}{ Logit Models } & & & \multicolumn{2}{c}{ Tobit model } \\
\cline { 2 - 5 } & Model 1 & Model 2 & Model 3 & Model 4 & Model 5 & Model 6 \\
\hline Prob $>\operatorname{chi}^{2}\left(\chi^{2}\right)$ & 0.01 & 0.00 & 0.04 & 0.00 & 0.11 & 0.00 \\
Pseudo $R^{2}$ & 0.16 & 0.19 & 0.16 & 0.27 & 0.49 & 0.09 \\
\hline
\end{tabular}

${ }^{a}$ Robust standard errors are in parentheses, Odds ratios are reported in the regression results; $* * *, * *$, and $*$ refer to $p<0.01, p<0.05$, and $p<0.1$, respectively

${ }^{\mathrm{b}}$ Matched with coding in Table 5, Official information refers to information only from the government; All information refers to information either from relatives, friends, and the media or from the government. They both take $1=$ information only from oneself or relatives and friends as the reference group

${ }^{\mathrm{c}}$ Binary variables take 0 corresponding category as the reference group

\section{Discussion}

Based on survey data from farming households in landslide threat areas of southwestern China, and under the guidance of the psychological measurement paradigm, this study measured multiple dimensions of risk perception and sense of place. Econometric regression models were constructed to explore the impacts of farming households' risk perception and sense of place on their preparedness for disasters (whether the households adopted any of the five types of disaster preparedness behaviors, and the total number of behaviors adopted). Like the empirical research results reported from most countries, only a relatively small proportion of the surveyed households were prepared for disasters in these disaster-threatened areas. Among the sampled households, $67 \%$ were not prepared for disasters at all, and only $2 \%$ adopted four types of disaster preparedness behaviors out of five.

Risk perception is often regarded as an important factor affecting farming households' disaster preparedness, but different studies have obtained different results regarding this relationship. Under the guidance of the psychological measurement paradigm, combined with the actual situation of the study area, this study broadens the examination of risk perception by constructing logistic and Tobit regression models to explore the correlations between the various dimensions of disaster risk perception and farming households' disaster preparedness behaviors. There are similarities and differences between the results of this study and other similar studies. The results are inconsistent with those of Lindell and Whitney (2000), Siegrist and Gutscher (2006), Miceli et al. (2008), and McNeill et al. (2013). Lindell and Whitney (2000) and Siegrist and Gutscher (2006) found that there was no significant correlation between risk perception and disaster preparedness. Miceli et al. (2008) found no relationship between likelihood judgments and the adoption of protective behaviors, while feelings of worry were associated with disaster preparedness. McNeill et al. (2013) found that perceived threat severity was associated with disaster preparedness, while the relationship between perceived threat likelihood and disaster preparedness was weak. Han et al. (2017) found that the perceived consequences and worry were relatively significantly correlated with adopting more kinds of preparedness activities. Cui et al. (2018) found that respondents who volunteered for disaster risk reduction activities received geological disaster education and participated in evacuation drills, leading to a perception of higher community resilience. This study found that households with higher scores on Probability and Threat were more likely to adopt a greater number of disaster preparedness behaviors (such as preparing necessary items), while households with higher scores on Controllability were less likely to adopt a high total number of disaster preparedness behaviors.

Sense of place, place attachment, and community ties are also often regarded as important factors that affect farming households' disaster preparedness, although the results are inconsistent. Bachrach and Zautra (1985), Tierney et al. (2001), Mishra et al. (2010), and Anton and Lawrence (2016) found that the stronger the place attachment or community ties of households, the more likely they were to be prepared for a disaster. This is consistent with this study, which found that households with higher scores for Place dependence were more likely to show disaster preparedness. This study is also consistent with those of Duncan and Newman (1975), Kiecolt and Nigg (1982), Riad and Norris (1998), and Brenkert-Smith et al. (2006), who found that individuals who intended to move were less embedded in the community. Residents would weigh the relationship between the need for disaster prevention, sense of place (that is their attachment to place), and their true feelings of living in a threat area, and unless they were directly threatened by a disaster, they were unwilling to prepare for one.

In addition to risk perception, sense of place, and other psychological factors, the individual and household socioeconomic characteristics of the interviewees were 
also important influences on their disaster preparedness. Consistent with most studies (Edwards 1993; Russell et al. 1995; Beringer 2000; Collins 2008; Basolo et al. 2009; Fischer 2011; Brenkert-Smith et al. 2012; Reininger et al. 2013; Hoffmann and Muttarak 2017), in this study, farming households' various disaster preparedness behaviors were related to the different socioeconomic characteristics of the respondents. The total number of disaster preparedness behaviors (Y6) was related to Education, Distance, and information access channels, for example.

Compared to previous studies, the multidimensional measurement of risk perception and sense of place, and the use of multiple regression methods, provide some new ideas that can be a reference for similar research and enhance our understanding of farming households' disaster preparedness behaviors and their influencing factors in disaster threat areas. However, there are still some deficiencies in this study: it only focused on the disaster preparedness of residents in landslide-threatened areas, for example. Whether the conclusions and policy implications of this study apply to other types of mountain hazard threat areas (such as mudslides, earthquakes, and so on) still requires further exploration. It is necessary to conduct further comparative research on disaster preparedness of rural households in different types of mountain hazard threat areas. These deficiencies can be accounted for in future studies.

\section{Conclusion}

Using survey data obtained from farming households in a landslide-threatened area, this study established binary logistic regression models and a Tobit model to explore the relationship between farming household risk perception and sense of place and disaster preparedness behaviors. The results show that: (1) Farming households' disaster preparedness awareness was relatively low, and their disaster preparedness behaviors were mainly based on their own learning. (2) Risk perception and sense of place are important factors that affect the disaster preparedness behavior of farming households. Probability, Threat, and Controllability were significantly related to the total number of adopted disaster preparedness behaviors. Farming households with higher scores on Place dependence were more likely to adopt greater numbers of disaster preparedness behaviors; individual and household characteristics also had significant relationships with household disaster preparedness behavior.

Acknowledgements We gratefully acknowledge the financial support from the National Natural Science Foundation of China (Grant No. 41771194); the West Light Foundation of the Chinese Academy of Sciences (Y5R2080080); the 135 Strategic Program of the Institute of Mountain Hazards and Environment, Chinese Academy of Science (sds-135-1703); the Youth Talent Team Program of the Institute of Mountain Hazards and Environment, Chinese Academy of Sciences (SDSQB-2015-01); and the Youth Innovation Promotion Association, Chinese Academy of Sciences (2016332). The authors also extend great gratitude to the anonymous reviewers and the editors for their helpful reviews and critical comments.

Open Access This article is distributed under the terms of the Creative Commons Attribution 4.0 International License (http://crea tivecommons.org/licenses/by/4.0/), which permits unrestricted use, distribution, and reproduction in any medium, provided you give appropriate credit to the original author(s) and the source, provide a link to the Creative Commons license, and indicate if changes were made.

\section{References}

Adiyoso, W., and H. Kanegae. 2014. The role of Islamic teachings in encouraging people to take tsunami preparedness in Aceh and Yogyakarta Indonesia. In Recovery from the Indian Ocean Tsunami: A ten-year journey, ed. R. Shaw, 259-278. Tokyo: Springer Japan.

Anton, C.E., and C. Lawrence. 2016. Does place attachment predict wildfire mitigation and preparedness? A comparison of wildlandurban interface and rural communities. Environmental Management 57(1): 148-162.

Armaş, I., and E. Avram. 2008. Patterns and trends in the perception of seismic risk. Case study: Bucharest Municipality/Romania. Natural Hazards 44(1): 147-161.

Bachrach, K.M., and A.J. Zautra. 1985. Coping with a community stressor: The threat of a hazardous waste facility. Journal of Health and Social Behavior 26(2): 127-141.

Baker, E.J. 2011. Household preparedness for the aftermath of hurricanes in Florida. Applied Geography 31(1): 46-52.

Beringer, J. 2000. Community fire safety at the urban/rural interface: The bushfire risk. Fire Safety Journal 35(1): 1-23.

Basolo, V., L.J. Steinberg, R.J. Burby, J. Levine, A.M. Cruz, and C. Huang. 2009. The effects of confidence in government and information on perceived and actual preparedness for disasters. Environment and Behavior 41(3): 338-364.

Brenkert-Smith, H., P.A. Champ, and N. Flores. 2006. Insights into wildfire mitigation decisions among wild and urban interface residents. Society \& Natural Resources 19(8): 759-768.

Brenkert-Smith, H., P.A. Champ, and N. Flores. 2012. Trying not to get burned: Understanding homeowners' wildfire risk-mitigation behaviors. Environmental Management 50(6): 1139-1151.

Butler, D.R., and L.M. DeChano. 2012. Landslide risk perception, knowledge and associated risk management: Case studies and general lessons from Glacier National Park, Montana, USA. In Landslide hazard and risk, ed. T. Glade, M. Anderson, and M.J. Crozier, 199-218. West Sussex, England: John Wiley \& Sons.

Calvello, M., M.N. Papa, J. Pratschke, and M.N. Crescenzo. 2016. Landslide risk perception: A case study in southern Italy. Landslides 13(2): 349-360.

Chongqing Municipal Bureau of Statistics. 2015. Chongqing statistical yearbook 2014. Chongqing: Chongqing Statistical Press (in Chinese).

CNSB (China National Statistical Bureau). 2015. China yearbook of household survey in 2014. Beijing: China Statistical Press (in Chinese). 
Collins, T.W. 2008. What influences hazard mitigation? Household decision making about wildfire risks in Arizona's white mountains. Professional Geographer 60(4): 508-526.

Cui, K., Z. Han, and D. Wang. 2018. Resilience of an earthquakestricken rural community in southwest China: Correlation with disaster risk reduction efforts. International Journal of Environmental Research and Public Health 15(3): 407-421.

Duncan, G., and S. Newman. 1975. People as planners: The fulfillment of residential mobility expectations. In Five thousand American families: Patterns of economic progress, ed. G.J. Duncan, and J. Morgan, 279-318. Ann Arbor: Institute of Social Research, University of Michigan.

Edwards, M.L. 1993. Social location and self-protective behavior: Implications for earthquake preparedness. International Journal of Mass Emergencies and Disasters 11(3): 293-303.

Fischer, A.P. 2011. Reducing hazardous fuels on nonindustrial private forests: Factors influencing landowner decisions. Journal of Forestry 109(5): 260-266.

Geological Disaster Emergency Response Directing Center of Ministry of Land and Resources. 2016. National geological disasters bulletin in 2016. Beijing: China Statistical Press (in Chinese).

Godschalk, D.R., A. Rose, E. Mittler, K. Porter, and C.T. West. 2009. Estimating the value of foresight: Aggregate analysis of natural hazard mitigation benefits and costs. Journal of Environmental Planning and Management 52(6): 739-756.

Guo, J. 2008. Alternative paradigms of volcanic risk perception: The case of Mt. Pinatubo in the Philippines. Journal of Volcanology and Geothermal Research 172(3): 315-328.

Guo, S., S. Liu, L. Peng, and H. Wang. 2014. The impact of severe natural disasters on the livelihoods of farmers in mountainous areas: A case study of Qingping township, Mianzhu city. Natural Hazards 73(3): 1679-1696.

Han, Z., and J. Nigg. 2011.The influences of business and decision makers' characteristics on disaster preparedness-A study on the 1989 Loma Prieta earthquake. International Journal of Disaster Risk Science 2(4): 22-31.

Han, Z., H. Wang, Q. Du, and Y. Zeng. 2017. Natural hazards preparedness in Taiwan: A comparison between households with and without disabled members. Health Security 15(6): 575-581.

Harvatt, J., J. Petts, and J. Chilvers. 2011. Understanding householder responses to natural hazards: Flooding and sea-level rise comparisons. Journal of Risk Research 14(1): 63-83.

He, Z., and G.F. Zhai. 2015. Spatial effect on public risk perception of natural disaster: A comparative study in East Asia. Journal of Risk Analysis and Crisis Response 5(3): 161-168.

Hernández-Moreno, G., and I. Alcántara-Ayala. 2017. Landslide risk perception in Mexico: A research gate into public awareness and knowledge. Landslides 14(1): 351-371.

Hoffmann, R., and R. Muttarak. 2017. Learn from the past, prepare for the future: impacts of education and experience on disaster preparedness in the Philippines and Thailand. World Development 96: 32-51.

Jones, E.C., A.J. Faas, A.D. Murphy, G.A Tobin, L.M. Whiteford, and C. McCarty. 2013. Cross-cultural and site-based influences on demographic, well-being, and social network predictors of risk perception in hazard and disaster settings in Ecuador and Mexico. Human Nature 24(1): 5-32.

Jorgensen, B.S., and R.C. Stedman. 2001. Sense of place as an attitude: Lakeshore property owners' attitudes toward their properties. Journal of Environmental Psychology 21(3): 233-248.

Kiecolt, K.J., and J.M. Nigg. 1982. Mobility and perceptions of a hazardous environment. Environment and Behavior 14(2): 131-154.
Kohn, S., J.L. Eaton, S. Feroz, A.A. Bainbridge, J. Hoolachan, and D.J. Barnett. 2012. Personal disaster preparedness: An integrative review of the literature. Disaster Medicine and Public Health Preparedness 6(3): 217-231.

Lawrence, J., D. Quade, and J. Becker. 2014. Integrating the effects of flood experience on risk perception with responses to changing climate risk. Natural Hazards 74(3): 1773-1794.

Lazo, J.K., A. Bostrom, R.E. Morss, J.L. Demuth, and H. Lazrus. 2015. Factors affecting hurricane evacuation intentions. Risk Analysis 35(10): 1837-1857.

Lindell, M.K. 2013. North American cities at risk: Household responses to environmental hazards. In Cities at risk, ed. H. Joffe, T. Rossetto, and J. Adams, 109-130. New York and London: Springer.

Lindell, M.K., and S.N. Hwang. 2008. Households' perceived personal risk and responses in a multihazard environment. Risk Analysis 28(2): 539-556.

Lindell, M.K., and R.W Perry. 2000. Household adjustment to earthquake hazard: A review of research. Environment and Behavior 32(4): 461-501.

Lindell, M.K., and R.W. Perry. 2003. Communicating environmental risk in multiethnic communities. Thousand Oaks, CA: Sage Publications.

Lindell, M.K., and D.J. Whitney. 2000. Correlates of household seismic hazard adjustment adoption. Risk Analysis 20(1): 13-25.

Martin, W.E., I.M. Martin, and B. Kent. 2009. The role of risk perceptions in the risk mitigation process: The case of wildfire in high risk communities. Journal of Environmental Management 91(2): 489-498.

McClure, J., D. Johnston, L. Henrich, T.L. Milfont, and J. Becker. 2015. When a hazard occurs where it is not expected: Risk judgments about different regions after the Christchurch earthquakes. Natural Hazards 75(1): 635-652.

McNeill, I.M., P.D. Dunlop, J.B. Heath, T.C. Skinner, and D.L. Morrison. 2013. Expecting the unexpected: Predicting physiological and psychological wildfire preparedness from perceived risk, responsibility, and obstacles. Risk Analysis 33(10): 1829-1843.

Miceli, R., I. Sotgiu, and M. Settanni. 2008. Disaster preparedness and perception of flood risk: A study in an alpine valley in Italy. Journal of Environmental Psychology 28(2): 164-173.

Mishra, S., S. Mazumdar, and D. Suar. 2010. Place attachment and flood preparedness. Journal of Environmental Psychology 30(2): 187-197.

Mulilis, J.P., T.S. Duval, and R. Lippa. 1990. The effects of a large destructive local earthquake on earthquake preparedness as assessed by an earthquake preparedness scale. Natural Hazards 3(4): 357-371.

Paul, B.K., and R.H. Bhuiyan. 2010. Urban earthquake hazard: Perceived seismic risk and preparedness in Dhaka city, Bangladesh. Disasters 34(2): 337-359.

Peacock, W.G., S.D. Brody, and W. Highfield. 2005. Hurricane risk perceptions among Florida's single family homeowners. Landscape and Urban Planning 73(2-3): 120-135.

Peng, L., L. Lin, S.Q. Liu, and D. Xu. 2017. Interaction between risk perception and sense of place in disaster-prone mountain areas: A case study in China's Three Gorges Reservoir Area. Natural Hazards 85(2): 777-792.

Perry, R.W. 1979. Evacuation decision-making in natural disasters. Mass Emergencies 4(1): 25-38.

Reininger, B.M., M.H. Rahbar, M. Lee, Z. Chen, S.R. Alam, J. Pope, and B. Adams. 2013. Social capital and disaster preparedness among low income Mexican Americans in a disaster prone area. Social Science \& Medicine 83(1): 50-60.

Riad, J.K., and F.H Norris. 1998. Hurricane threat and evacuation intentions: An analysis of risk perception, preparedness, social 
influence, and resources. Newark, DE: Disaster Research Center, University of Delaware.

Roder, G., T. Ruljigaljig, C.W. Lin, and P. Tarolli. 2016. Natural hazards knowledge and risk perception of Wujie indigenous community in Taiwan. Natural Hazards 81(1): 641-662.

Russell, L.A., J.D. Goltz, and L.B. Bourque. 1995. Preparedness and hazard mitigation actions before and after two earthquakes. Environment and Behavior 27(6): 744-770.

Siegrist, M., and H. Gutscher. 2006. Flooding risks: A comparison of lay people's perceptions and expert's assessments in Switzerland. Risk Analysis 26(4): 971-979.

Slovic, P. 1987. Perception of risk. Science 236(4799): 280-285.

Tierney, K.J. 1993. Disaster preparedness and response: Research findings and guidance from the social science literature. Newark, DE: Disaster Research Center, University of Delaware.

Tierney, K.J., M.K Lindell, and R.W. Perry. 2001. Facing the unexpected: Disaster preparedness in the United States. Washington, DC: Joseph Henry Press.

Tobin, G.A., L.M. Whiteford, E.C. Jones, A.D. Murphy, S.J. Garren, and C.V. Padros. 2011. The role of individual well-being in risk perception and evacuation for chronic vs. acute natural hazards in Mexico. Applied Geography 31(2): 700-711.

Weinstein, N.D. 1992. The precaution adoption process. Health Psychology 7(4): 355-386.

Xu, D., L. Peng, S. Liu, C. Su, X. Wang, and T. Chen. 2017a. Influences of sense of place on farming households' relocation willingness in areas threatened by geological disasters: Evidence from China. International Journal of Disaster Risk Science 8(1): 16-32.

Xu, D., L. Peng, S. Liu, C. Su, X. Wang, and T. Chen. 2017b. Influences of migrant work income on the poverty vulnerability disaster threatened area: A case study of the Three Gorges Reservoir area, China. International Journal of Disaster Risk Reduction 22: 62-70.

Xu, D., L. Peng, C. Su, S. Liu, X. Wang, and T. Chen. 2016. Influences of mass monitoring and mass prevention systems on peasant households' disaster risk perception in the landslidethreatened Three Gorges Reservoir Area, China. Habitat International 58: 23-33. 